\section{The economic burden of pneumoconiosis in China}

\section{Y X Liang, O Wong, H Fu, T X Hu, S Z Xue}

\section{Occupational safety and health programmes are economically beneficial}

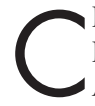
the active labour force, of which a large proportion is engaged in construction, mining, and other occupations with potential exposure to silica. The number of workers exposed to silica containing dusts may be as high as 12 million. Pneumoconiosis has long been the most serious and yet preventable occupational disease in China. New cases are estimated at 7500 to 10000 annually, representing more than $70 \%$ of the total reported cases of occupational diseases in recent years. ${ }^{1-3}$ The cumulative number of confirmed pneumoconiosis cases recorded in China between 1949 and 2001 reached 569 129. The majority of the cases occurred in the mining industries, particularly in coalmines, resulting in anthracosilicosis, which accounted for about $40 \%$ of the disease. Among them, more than 25\% had died. In addition to confirmed cases, a 1986 nationwide survey found that an even greater number of exposed workers (around 600 000) were classified as suspected cases. ${ }^{1-3}$

\section{ECONOMIC BURDEN ANALYSIS}

Pneumoconiosis is a progressive and irreversible fibrogenic lung disease that results in not only human suffering but also unaffordable economic burdens. In this paper, we estimate the economic burden of pneumoconiosis in China. The methodologies of estimating economic burdens of occupational diseases vary from disease to disease and from investigation to investigation, dictated primarily by the data available. ${ }^{4-8}$ We use the hina, with a population of 1.2 billion, is the most populous country. Approximately 700 million are in

traditional human capital approach, which divides costs into direct and indirect categories. In our analysis, direct costs include medical expenses, work absence losses, and management costs, whereas indirect costs include production and profit/tax losses due to work absences. The data in our analysis are derived from two previous investigations in China. ${ }^{910}$

The first investigation is based on a 1986 national survey of economic losses associated with pneumoconiosis in several key industries in 10 provinces and selected cities in China. ${ }^{9}$ Table 1 presents a summary of the findings of the survey. The average direct and indirect costs were $¥ 2869$ and $¥ 12896$ per person per year, respectively, and the total economic loss was $¥ 15765$ per person per year. [Note: $¥$ is the symbol for "yuan" in the Chinese currency Renminbi (RMB). US\$1 is approximately $¥ 8.2$. To put these figures in perspective, the typical monthly wage for a non-professional worker was $¥ 400$ in 1986 and $¥ 1500$ in 2002.]

\section{"Economic losses represented $0.4 \%$ of China's GNP"}

It was estimated that there were 310000 cases of pneumoconiosis in China in 1986. Based on the above estimates, the total yearly economic losses would have been $¥ 5$ billion in 1986. However, it should be noted that according to market value replacement, the value of $¥ 1$ in the late 1990s was devaluated to about one fifth of that in the mid-1980s. Therefore, based on the above estimates, the annual economic

Table 1 Estimated economic losses due to pneumoconiosis (per person) in China, 1986

\begin{tabular}{lll}
\hline Data source & Direct costs & Indirect costs \\
\hline 20 plants in Shanghai & $¥ 2623$ & $¥ 30732$ \\
10 provinces or cities in other parts of China & $¥ 3030$ & $¥ 8925$ \\
13 coal mines in other parts of China & $¥ 2620$ & $¥ 6892$ \\
4 non-ferrous metal mines in other parts of China & $¥ 3202$ & $¥ 5035$ \\
Average & $¥ 2869$ & $¥ 12896$ \\
\hline
\end{tabular}

Source: Ministry of Health, People's Republic of China.? losses associated with pneumoconiosis would have been $¥ 25$ billion. This figure represents $0.4 \%$ of China's total gross national product (GNP), which was around $¥ 6000$ billion or US\$750 billion in 1999.

The second investigation was conducted in Shanghai in 1992, consisting of 2164 foundry workers at a machinery factory, who had been exposed to silica containing dust for more than one year. ${ }^{10}$ A total of 108 workers were diagnosed with pneumoconiosis during 1988-92. The prevalent cases of pneumoconiosis between 1988 and 1992 ranged from 80 to 84 in the factory. The dust exposure level was as high as $130 \mathrm{mg} / \mathrm{m}^{3}$ during the early 1960s. Dust controls and corrective measures implemented since the mid-1960s were successful in lowering dust level to $2.9 \mathrm{mg} / \mathrm{m}^{3}$ in 1992; the prevalence of pneumoconiosis was dramatically reduced.

The average direct economic loss for the prevalent cases of pneumoconiosis between 1988 and 1992 was estimated to be $¥ 3736$ per person per year. In addition, the fatalities of pneumoconiosis during that period brought about another source of direct economic losses: death compensation and funeral expenses, estimated at $¥ 3285$ per death. According to personnel records at the factory, about half of the workers with advanced pneumoconiosis had to leave work completely, which resulted in a tremendous decrease of production (estimated at $¥ 19800$ per person) and profits/tax losses (estimated at $¥ 4615$ per person), with the annual total indirect costs for each advanced pneumoconiosis case estimated at (¥19800+¥4615) or $¥ 24415$. Furthermore, in addition to the advanced cases, half of the workers remaining on the job with early or intermediate pneumoconiosis had about 105 sick days per year, which resulted in approximately one third of the production and profits/tax losses of those with advanced pneumoconiosis. For workers with early or intermediate pneumoconiosis who remained on the job, the indirect losses were roughly one third of those at the advanced stage-that is, $¥ 8057$ per person. Therefore, the average indirect costs resulted from a worker suffering from silicosis were ( $¥ 24415$ + $¥ 8057) / 2$ or $¥ 16236$ per person per year.

The total economic burden equalled the sum of direct costs and indirect costs resulting from the prevalent cases of pneumoconiosis as well as death compensation and funeral expenses for patients who died in the fiscal year. The annual economic burden associated with pneumoconiosis could be estimated as follows: the number of prevalent cases in the year $\times($ direct + indirect costs $)+$ number of death of the year $\times$ (death compensation and funeral expenses). An estimate of the total economic losses as a 
result of pneumoconiosis in China can be obtained by applying the Shanghai survey data to national statistics. According to national statistics, the average annual number of pneumoconiosis survivors was 390089 during 1949-96. ${ }^{1}$ With an annual death rate of approximately $1.2 \%$ for pneumoconiosis, the number of deaths was estimated to be approximately 5000 per year. The annual total economic losses to China as a result of pneumoconiosis, based on data from the Shanghai survey, can be estimated as follows: $390089 \times(¥ 3736+¥ 16236)+$ $5000 \times ¥ 3285=¥ 7.81$ billion (US\$978 million). This figure accounted for $0.39 \%$ of China’s GNP in 1992 ( $¥ 2022$ billion), and is remarkably close to the estimate developed earlier, based on the 1986 national survey described in the first example. By way of comparison, the total personal income tax received by the central government was only $0.6 \%$ of GNP in 2000 .

\section{COST-BENEFIT ANALYSIS}

The working conditions in the foundry workshops of the machinery factory in the Shanghai investigation were quite poor in the 1960s, with an average air concentration of silica containing dust of $130.1 \mathrm{mg} / \mathrm{m}^{3}$, which was 65 times the maximum allowable concentration (MAC) of $2 \mathrm{mg} / \mathrm{m}^{3}$ adopted in China. After the implementation of dust control measures, average dust concentration was reduced to $3.9 \mathrm{mg} / \mathrm{m}^{3}$ in 1992 . Had dust control measures not been implemented, the 2164 foundry workers at the machinery factory would have continued to be exposed to much higher dust levels, which would have been expected to induce approximately 664 new cases of pneumoconiosis during 1988-92. ${ }^{10}$ However, the actual number of observed cases of pneumoconiosis was only 108; 556 cases of pneumoconiosis had thus been prevented as a result of the reduction of dust exposure.

The economic benefit from the reduction of cases of silicosis can be calculated as follows:
- Benefit from avoiding direct loss (medical costs only): $¥ 3736 \times 556=$ $¥ 2.08$ million.

- Cumulative saving of workforce after dust being controlled: 8340 personyears $(=556 \times 15$ additional years of work per worker).

- Benefits from avoiding indirect loss (profits/tax): $¥ 16236 \times 8340$ personyears $=¥ 135.40$ million.

- Total benefits from the prevention: $¥ 2.08$ million $+¥ 135.40$ million = $¥ 137.48$ million

The total costs of dust reduction measures at the Shanghai machinery factory were approximately ¥10 million over a period of 30 years, 1963-92. Thus, the ratio of benefit to cost was $¥ 137.48$ million/ $¥ 10$ million $=13.7$. The return of investment of preventive measures was considerable as indicated by this high benefit-cost ratio.

\section{CONCLUSION}

The estimated economic losses based on both the national survey and the Shanghai investigation were remarkably close. The estimated economic losses to China associated with pneumoconiosis account for approximately $0.4 \%$ of the GNP. Therefore, this highly preventable disease has brought not only unnecessary human suffering but also unaffordable economic burdens. Neither the health consequences nor the economic burdens are acceptable or affordable. As illustrated by the Shanghai data, dust controls are effective measures in reducing both the number of pneumoconiosis cases and associated economic burden.

These data underscore the importance of showing the relation between health, productivity, and economic impact of occupational health and safety programmes on national economy. Unfortunately, programmes of occupational safety and health have often been regarded as a burden to the economy of the industry and the nation. However, recent economic appraisals show totally different results: that is, such programmes save not only lives but also money. Occupational safety and health programmes have been found to be economically beneficial, and benefit-cost ratios in many situations are surprisingly high. It is important to publicise such results to increase the awareness of both political and economic decision makers of the benefits of occupational safety and health programmes.

Occup Environ Med 2003;60:383-384

\section{Authors' affiliations}

Y X Liang, O Wong, H Fu, S Z Xue, School of Public Health, Fudan University, Shanghai, China

T X Hu, Shanghai Municipal Center for Disease Control and Prevention, Shanghai, China

Correspondence to: $\operatorname{Dr} Y X$ Liang, Department of Occupational Health, School of Public Health, Fudan University, 138 Yixueyuan Road,

Shanghai 200032, China:

yxliang@shmu.edu.cn

\section{REFERENCES}

1 Zou CQ, Gao Y, Ma QY. Pneumoconiosis in China. Asian-Pacific Newsletter on Occupational Health and Safety 1997;4(2):44-9.

2 Liang YX, Fu $H, G \cup X Q$. Provision of occupational health services in China. Asian-Pacific Newsletter on Occupational Asian-Pacific Newsletter on Occupation
Health and Safety 1998;5(2):34-9.

3 Liang YX, Fu H. Coping with new challenges of occupational health in the 21 st century [in Chinese]. Chinese J Ind Hyg Occup Dis 2001:19:319-20.

4 van Beeck EF, van Roijen, L, Mackenbach JP. Medical costs and economic production losses due to injuries in the Netherlands. J Trauma 1997;42: $1116-23$

5 Leigh JP. Compensating wages, value of a statistical life, and inter-industry differentials. J Environ Econ Manage 1995;28:83-97.

6 Leigh JP, Markowitz SB, Fahs M, et al.

6 Leigh JP, Markowitz SB, Fahs M, et al. Estimates of costs, morbidity and mortality. Arch Intern Med 1997; 157:1557-68.

7 Burger ML, Murray JF, Xu J, et al. Alternative valuations of work loss and productivity. J Occup Environ Med 2001;43:18-24.

8 Weil D. Valuing the economic consequences of work injury and illness: a comparison of methods and findings. Am J Ind Med 2001;40:418-37.

9 Ministry of Health, People's Republic of China. A nationwide epidemiological survey of pneumoconiosis [in Chinese]. Beijing, 1992

10 Gou CP. A cost-effectiveness analysis of dust control measures at a foundry [in Chinese]. J Labor Med 1994;11(suppl):47-9. 